4. Its peculiar form and arrangement are but one of the expressions of the high degree of specialization of the avian eye in the direction of increased efficiency as an optical instrument.

\title{
BIBLIOGRAPHY
}

Leuckart, R.-Graefe-Saemisch Handbuch der Gesamten Augenheilk., p. 145, Cap. 7. Vol. II., 1876.

Mihalkovics. - Untersuchungen uber den Kamm des Vogelauges. Arch. $f$. mikros., Anat., Bd. 9, 1873.

Denissenko.- Uber den Bau und die Function des Kammes. Arch. f. mikros.,. Anat., Bd. 19, 1881.

Gegenbauer, C.- Vergleichende Anat. der Wirbelthiere, Leipzig, 1898.

Rabl.-Uber den Bau und Entwicklung der Linse. Zeitsch. f. wiss Zool., Vol. LXIII, 1898.

Bernd.-Inaugural Dissertation. Bonn. 1905.

Franz.-Der Facher im Auge der Vogel. Biol. Zentralbl., Vol. XXVIII, 1908.

Casey Wood. -The Fundus Oculi of Birds. Chicago, 1917.

Mann.-Brit. Jl. of Ophthal., April, 1922.

Beauregarde.-Comptes rend. et mem. Soc. de Biol., Paris, pp. 132-136, 1875.

Abelsdorff.-Arch. f. vergleich Ophthal., Heft. 3, No. 3, pp. 290-292, 1910.

\section{A CASE OF RECURRENT DETACHMENT OF THE RETINA}

BY

H. C. HigheT, M. D.

WINCHESTER

In the January issue of this journal, Sir William Lister deals exhaustively with holes in the retina and their relation to detachment, either of the sudden type or as a result of the presence of a new growth.

Towards the end of his most interesting communication he remarks: "Personally, I have seen no case in which there was a hole improve spontaneously or after treatment, and it is my opinion that with our present available methods such cases of detachment are practically hopeless." In order to supplement his own experience, he asks for further data with regard to the aetiology of holes in the retina, improvement in the clinical methods of detecting whether the retina is being pushed in by fluid from without or dragged in by adherent and contracting vitreous, and lastly for reports of the practical experience of surgeons in the treatment of these cases, classified according to their cause.

It is in reply to the third request that I venture to report a case of what I have entitled "Recurrent Detachment of the Retina," a case in which within five months' three consecutive detachments were observed with apparent recovery. 
The case is as follows :

On May 9, 1923, I was asked to see a lady, aged 61 years, who had suddenly gone blind in her left eye' while sitting down to lunch during the previous day. There was no history of any injury to the eye or head, nor of any previous trouble with her eyes. There was no doubt, she told me, that the eye went wrong all at once. The only circumstance which might bear upon the aetiology was that she had been busy all the morning helping her maids in "spring-cleaning," and that she had assisted in moving the furniture. There was no pain in the eye which, on external examination, seemed to be in no way different from the right. Both pupils were equal as was also the tension. There was no circumcorneal injection, the cornea was free from any pathological condition and there was no tenderness on palpation. The eye, however, was totally blind without the slightest perception of light, and the ophthalmoscope failed to reveal even the faintest suspicion of any red reflex through the pupil. The radial pulse showed rather high arterial tension. A five per cent. solution of dionin drops was prescribed, and she was ordered to go to bed at once and to remain as much as possible flat on her back without a pillow under her head.

On May 16, a week later, she was seen at her own home when to my surprise she stated that her sight had come back. With her own glasses, +4D sph., she could read Snellen 1.5 with the left eye and 0.5 with the right. The ophthalmoscope showed nothing abnormal in cornea or lens, but there was a general haze of the vitreous with two large cob-web like floating opacities. The details of the fundus could not be made out and there was no evidence of retinai detachment.

Tension was still normal and the eye was free from pain.

The same treatment was continued, and on May 30, twenty-two days after the onset of the hlindness, the general opacity of the vitreous had cleared up so well that the details of the fundus could be seen and nothing abnormal could be found. The large floating opacities in the vitreous were rather less but still quite evident.

She was now allowed to leave her bed for a few hours every afternoon and evening, was cautioned against any violent exertion, and was advised to spend most of her time downstairs lying on a couch.

I did not see her again until July 4, when she came to me in a very despondent mood. Her story was that until June 23 her eye had improved steadily, but that suddenly on that day it had gone wrong again. At first the lower part of the field became blind and gradually the blindness became general, but some sight had come hack within the last few days. On examination an absolute scotoma was found in the lower half of the field, and corresponding 
to this a detachment was discovered involving nearly the whole upper half of the retina. She was ordered to bed again, a pad and handage were applied to the eye, and the dionin drops were prescribed again.

Three weeks later, on July 25, I noted that the detachment had disappeared, but that owing to the general fine haze in the vitreous the exact details of the funcius could not be clearly made out.

On September 5, rather less than four months after the onset of the initial detachment and rather less than two and a half months after the onset of the second detachment, a third detachment appeared just as suddenly as the others, but this time in the lower half of the retina only. It followed the same course as the others and by October 10, I was able to report that the detachment had completely righted itself. There was still considerable haze in the vitreous and visual acuity amounted to $6 / 36$ unaided and Snellen 2.5 with her glasses.

She was last seen on January 30,1924 , rather more than three and a half months after the third detachment was noted as having disappeared. The vitreous was now found to be quite clear, even the large cob-web opacities having gone, and the details of the fundus could clearly be made out. No trace of detachment was visible, and in fact, with the exception that the optic disc in the left eye seemed to be rather paler than its fellow in the right eye, nothing abnormal could be seen. Arteries and veins seemed normal and there were no signs of choroidal or retinal disturbance. Having already read Sir William Lister's communication I made a very careful search for holes in the retina but could discover none. Visual acuity now was reduced to $6 / 60$ with difficulty, owing to the distortion of objects which seemed broken in pieces.

In spite of the fact that no hole has as yet been detected in this case, the history of three consecutive detachments and the evident fluid character of the vitreous entitle us to infer the presence of a hole in the retina.

The aetiology is obscure. The patient is a healthy married woman, nearly 62 years of age, and the mother of a large family all now grown up and healthy. She has always enjoyed good health and the urine is free from albumen or sugar. It was impossible to get a Wassermann test, but I am confident that it would have proven negative. Refraction of both eyes gives $+1 \mathrm{D}$ sph. The presence of a new growth may be excluded.

Treatment consisted simply of rest in bed, the application of a light pad and bandage and the instillation of a five per cent. solution of dionin.

The prognosis is uncertain, but whether it is as hopeless as Sir William Lister makes out only time will tell. 